\title{
Influence of the Emulsifier System on Breakup and Coalescence of Oil Droplets during Atomization of Oil-In-Water Emulsions
}

\author{
Martha L. Taboada *(D), Nico Leister, Heike P. Karbstein ${ }^{(1)}$ and Volker Gaukel * \\ Institute of Process Engineering in Life Sciences, Food Process Engineering, Karlsruhe Institute of Technology, \\ 76131 Karlsruhe, Germany; nico.leister@kit.edu (N.L.); heike.karbstein@kit.edu (H.P.K.) \\ * Correspondence: martha.taboada@kit.edu (M.L.T.); volker.gaukel@kit.edu (V.G.)
}

Received: 20 May 2020; Accepted: 20 July 2020; Published: 3 August 2020

check for updates

\begin{abstract}
Spray drying of whey protein-based emulsions is a common task in food engineering. Lipophilic, low molecular weight emulsifiers including lecithin, citrem, and mono- and diglycerides, are commonly added to the formulations, as they are expected to improve the processing and shelf life stability of the products. During the atomization step of spray drying, the emulsions are subjected to high stresses, which can lead to breakup and subsequent coalescence of the oil droplets. The extent of these phenomena is expected to be greatly influenced by the emulsifiers in the system. The focus of this study was therefore set on the changes in the oil droplet size of whey protein-based emulsions during atomization, as affected by the addition of low molecular weight emulsifiers. Atomization experiments were performed with emulsions stabilized either with whey protein isolate (WPI), or with combinations of WPI and lecithin, WPI and citrem, and WPI and mono- and diglycerides. The addition of lecithin promoted oil droplet breakup during atomization and improved droplet stabilization against coalescence. The addition of citrem and of mono- and diglycerides did not affect oil droplet breakup, but greatly promoted coalescence of the oil droplets. In order to elucidate the underlying mechanisms, measurements of interfacial tensions and coalescence times in single droplets experiments were performed and correlated to the atomization experiments. The results on oil droplet breakup were in good accordance with the observed differences in the interfacial tension measurements. The results on oil droplet coalescence correlated only to a limited extent with the results of coalescence times of single droplet experiments.
\end{abstract}

Keywords: atomization; oil-in-water emulsions; droplet breakup; coalescence; emulsifiers

\section{Introduction}

The spray drying of protein-based oil-in-water $(o / w)$ emulsions is a common task in food engineering to produce a wide variety of products including infant formula, coffee creamers, and instant dairy powders. Typical formulations include a protein source such as whey or casein, an oil phase (e.g., milk fat or blends of vegetable oils), and a carbohydrate source (e.g., maltodextrin). Additional lipid-based low molecular weight emulsifiers (LMWEs) are usually included in the formulations, as they are expected to improve the processing as well as the shelf life stability of the product. The most commonly used LMWEs in foods include phospholipids (lecithins), mono- and diglycerides $(\mathrm{MoDi})$, and esters of fatty acids [1-3].

The oil droplet size distribution (ODSD) in the powder after spray drying is an important quality parameter, as it determines the functional properties and the stability of the powder and the reconstituted emulsion. For example, oil droplet size has been correlated to the bioavailability of specific fatty acids in infant formula and other functional foods $[4,5]$. The desired product-specific oil 
droplet size is usually adjusted in an emulsification step prior to the spray drying under the assumption that the oil droplet size remains unchanged in the subsequent processing steps. However, during atomization emulsions are subjected to high stresses, which can lead to deformation and breakup of the dispersed oil droplets. This has been already demonstrated for the atomization of whey protein stabilized emulsions with several atomization systems [6-9]. A previous study with pressure swirl atomizers showed that oil droplet breakup is highly dependent on the atomization pressure, while no influence of the nozzle geometry on the breakup was observed [6]. Coalescence of the oil droplets after breakup during atomization can also take place, as has been demonstrated by Kleinhans et al. [10] for the atomization of emulsions with effervescent atomizers. In summary, oil droplet breakup and coalescence during atomization can lead to uncontrolled modifications of a previously adjusted ODSD.

From the emulsification theory it is known that droplet breakup occurs when the external disruptive stresses exceed the droplet capillary pressure [11]. The ratio of disruptive to cohesive stresses is characterized by the capillary $(C a)$ or the Weber $(W e)$ number respectively, depending on whether the disruptive stresses are of a laminar or turbulent nature. In pressure swirl atomizers, the dominant disruptive stresses for oil droplet breakup are expected to be laminar [6]. An expression for the capillary number is depicted in Equation (1), where $\mu_{c}$ is the viscosity of the continuous phase, $\dot{\gamma}$ the shear rate, $x$ is the droplet diameter, and $\sigma$ is the interfacial tension between the continuous and the disperse phase. For breakup to occur, a critical value of $C a$ has to be exceeded, which depends on the viscosity ratio of the disperse and continuous phase $\mu_{d} / \mu_{c}$ [12]. The latter is replaced with the emulsion viscosity for emulsions with high disperse phase fractions [13].

$$
C a=\frac{\mu_{c} \dot{\gamma} x}{\sigma}
$$

The interfacial tension between the disperse and continuous phase is directly related to the emulsifier system. Due to their interfacial activity, the addition of LMWEs to the lipid phase is expected to influence possible changes in the oil droplet size during atomization. It is generally known that LMWEs can lower the interfacial tension faster and to a greater extent than protein emulsifiers and therefore lead to smaller droplets after homogenization processes [2]. This has been demonstrated for several emulsion systems combining LMWEs with protein emulsifiers [14-16].

From the emulsification theory it is also known that the resulting oil droplet size is not only a result of droplet breakup but also of the superimposed effect of coalescence [11]. By breaking up droplets, new interfaces are created, which need to be stabilized by the emulsifier system, before the droplets collide. Collision frequency and thus coalescence rate increases with the disperse phase content [17] and can only be excluded for very low disperse phase fractions $(<1 \%)$, and when enough emulsifier is available in the system [11]. The coalescence probability upon droplet collision depends especially on the adsorption kinetics of the emulsifier molecules and their stabilization mechanism. Due to their high molecular weight, proteins diffuse to the interface at a much lower rate than LMWEs. For proteins, at least partial denaturation is required at the interface to allow adsorption, making the stabilization process much slower than with LMWEs $[2,18]$. However, once adsorbed at the interface, strong viscoelastic films are formed, which resist mechanical stresses and provide better stabilization against coalescence $[2,18]$. LMWEs tend to diffuse faster to the interface, but their inability to form viscoelastic films make the interfaces less stable against coalescence [2].

When proteins and LMWEs are used simultaneously, different effects can take place at the interface. Competitive adsorption between LMWEs and proteins, as well as complete displacement of the protein from the interface by the LMWEs can occur. These aspects depend on the interfacial activity and hydrophobicity of the individual emulsifiers [2,19]. LMWEs and proteins can also form complexes with increased or decreased interfacial activity compared to the individual emulsifiers [2,19]. The named effects may either enhance or reduce the stability of emulsions against coalescence. It has been shown that the stabilizing or destabilizing effect is highly dependent on the concentration and type of LMWE and protein in the system [3,20-22]. Chen and Dickinson [23] found that adding monoglycerides up 
to a certain concentration led to smaller oil droplet sizes in emulsions stabilized with whey protein. Higher concentrations led to oil droplet coalescence presumably due to the presence of surfactant crystals at the interface and to unfavorable protein-surfactant interactions. Matsumiya et al. [24] showed that the addition of diglycerol esters of fatty acids promote severe coalescence of corn oil droplets stabilized with dairy proteins. Drapala et al. [16] showed that the addition of low levels of lecithin to whey protein hydrolysate (WPH)-based emulsions decreased the interfacial tension and led to the formation of smaller oil droplets during homogenization. However, the addition of high levels of lecithin (1-3\%) resulted in coalescence of oil droplets and bimodal distributions. Wang et al. [25] showed that the addition of lecithin in concentrations between $0.25 \%$ and $0.75 \%$ led to smaller oil droplet sizes and improved stability against coalescence, compared to emulsions stabilized with solely whey protein isolate (WPI). Bylaite et al. [26] also showed that the stability of $o / w$ emulsions stabilized with B-lactoglobulin could be improved by addition of soybean lecithin.

In spite of the relatively large amount of studies regarding the interactions between proteins and LMWEs in emulsions and interfaces, only a few studies have systematically studied the effects of LMWEs on the emulsion structure during atomization or spray drying of protein stabilized emulsions. Drapala et al. [3] studied the oil droplet size after powder reconstitution of spray dried emulsions stabilized with WPH in combination with lecithin and citric acid esters of mono- and diglycerides (citrem). An increase in the oil droplet size by addition of these emulsifiers was observed, compared to the system stabilized with sole WPH. To the authors' best knowledge, no published studies have investigated changes in the oil droplet size of whey protein-based emulsions during atomization, as affected by the addition of LMWEs. The aim of this study is therefore to investigate this aspect. Focus was set on the effect of LMWEs on oil droplet breakup and coalescence during atomization. For this task, atomization experiments were performed in a pilot scale with emulsions resembling typical spray dried food formulations. The addition of three commonly used lipid-based LMWEs was studied: lecithin, mono- and diglycerides (MoDi), and citrem. Oil droplet breakup was investigated by atomizing emulsions with $1 \mathrm{wt} . \%$ oil content, while the effect of coalescence was studied by atomizing emulsions with $30 \mathrm{wt} . \%$ oil.

Single droplet experiments are used by researchers to correlate interfacial properties and stability of droplets [27-29]. Dickinson et al. [28] studied the stabilizing properties of different protein types by measuring coalescence times and interfacial tension of single droplets. Neumann et al. [29] also measured interfacial tension and coalescence times in single droplets to study the interaction between two different emulsifiers in one system and the effect on the droplet stability. In this study, single droplet experiments were performed to measure interfacial tensions and coalescence times. The focus was set on the effect of the different LMWE/WPI systems on these properties. In contrast to other studies, single droplet experiments in this work were not only used to describe changes at the interface, but also to get information on the coalescence probability in the process. The results from the single droplet experiments were analyzed and correlated to the observed changes in the oil droplet size during the atomization experiments.

\section{Materials and Methods}

\subsection{Materials}

Whey protein isolate (WPI, Lacprodan ${ }^{\circledR}$ DI-9224) was obtained from Arla Food Ingredients (Sønderhøj, Denmark). The WPI composition was as follows: protein content $89.5 \%$, ash content $4.5 \%$, lactose content $<0.05 \%$, fat content $0.1 \%$, and moisture content $5 \%$. Maltodextrin (C DryTM MD 01910) with a dextrose equivalent value of 14 was obtained from Cargill ${ }^{\mathrm{TM}}$ (Haubordin, France) and had a moisture and ash content of $3.8 \%$ and $0.2 \%$, respectively. Medium-chain triglycerides oil (MCT oil, WITARIX ${ }^{\circledR}$ MCT 60/40) was supplied by IOI Oleo GmbH (Hamburg, Germany). The fatty acid composition was 56\% C-08 and 44\% C-10. Soybean lecithin (Metarin ${ }^{\mathrm{TM}}$ ) was obtained from Cargill $^{\mathrm{TM}}$ (Hamburg, Germany). Mono- and diglycerides of fatty acids (MoDi, Lamemul ${ }^{\circledR} \mathrm{K} 2000 \mathrm{~K}$ ) 
were obtained from BASF Personal Care and Nutrition GmbH (Monheim, Germany). Citric acid esters of mono- and diglycerides (citrem, GRINDSTED ${ }^{\circledR}$ CITREM N12) were obtained from DuPont Nutrition \& Biosciences (Brabrand, Denmark).

\subsection{Emulsion Preparation}

To investigate oil droplet breakup and coalescence separately, emulsions with $1 \mathrm{wt} . \%$ and $30 \mathrm{wt} . \%$ oil content were prepared. To adjust the initial oil droplet size independently of the oil content, the emulsions were prepared in a two-step process. In the first step, premix emulsions consisting of an aqueous whey protein solution (10 wt.\%), and MCT oil with LMWE (1 wt.\%, lecithin, citrem, or $\mathrm{MoDi}$ ) and water were prepared. For this, whey protein was dissolved in water and the $\mathrm{pH}$ was adjusted to 7.0 using a $0.5 \mathrm{M}$ solution of sodium hydroxide. The corresponding LMWE was added to the oil, which was heated up to $60{ }^{\circ} \mathrm{C}$ to ensure complete dissolution. The oil phase was added to the water phase at a ratio of 1:1 and the premix was homogenized for $2 \mathrm{~min}$ in a colloid mill (IKA magic $\mathrm{LAB}^{\circledR}, \mathrm{IKA}^{\circledR}$-Werke GmbH \& Co. KG, Staufen, Germany) operated at a gap width of $0.16 \mathrm{~mm}$ and a circumferential speed of $26 \mathrm{~m} / \mathrm{s}$. The emulsions were stored overnight to ensure equilibrium conditions at the oil/water interface. In the second step, right before atomization, the homogenized emulsions were diluted with the continuous phase, namely a solution of maltodextrin and water. To investigate oil droplet breakup excluding the influence of coalescence, the emulsions were diluted to an oil content of $1 \mathrm{wt} . \%$. The influence of coalescence was investigated by diluting emulsions to an oil content of $30 \mathrm{wt} . \%$. The ratio of WPI, LMWE, and MCT oil after dilution was kept constant at 1:0.1:10, which is within the range commonly used for spray dried emulsion products. As comparison, emulsions without added lipid-based LMWEs were also prepared. The composition of the studied emulsions are summarized in Table 1.

Table 1. Summary of the composition of emulsions for atomization experiments. All reported values refer to the total emulsion. $\mathrm{MCT}=$ medium-chain triglycerides; $\mathrm{WPI}=$ whey protein isolate; LMWE = low molecular weight emulsifier.

\begin{tabular}{|c|c|c|c|c|}
\hline MCT oil (wt.\%) & WPI (wt.\%) & LMWE (wt.\%) & Maltodextrin (wt.\%) & Water (wt.\%) \\
\hline \multirow{2}{*}{1} & \multirow{2}{*}{0.1} & - & \multirow{2}{*}{34.3} & 64.6 \\
\hline & & 0.01 & & 64.59 \\
\hline \multirow{2}{*}{30} & \multirow{2}{*}{3} & - & \multirow{2}{*}{14.3} & 52.7 \\
\hline & & 0.3 & & 52.4 \\
\hline
\end{tabular}

To ensure constant stresses during atomization in spite of the different oil contents, it was necessary to adjust the viscosity of the emulsions to the same value. This was done by setting the concentration of maltodextrin in the continuous phase to $34.4 \mathrm{wt} . \%$ and $14.3 \mathrm{wt} . \%$ for the emulsions with $1 \mathrm{wt} . \%$ and $30 \mathrm{wt} . \%$ oil, respectively. By this, the viscosity ratio as well as the stresses during atomization were set to the same value. Viscosities were measured by rotational rheometry (Physica MCR 101/301, Anton Paar, Graz, Austria) with a double gap geometry at $20^{\circ} \mathrm{C}$. A logarithmic shear rate controlled ramp of $1-1000 \mathrm{~s}^{-1}$ was performed. All emulsions presented an almost Newtonian behavior. The mean viscosity at a shear rate of $1000 \mathrm{~s}^{-1}$ was $31.6 \mathrm{mPa} \cdot \mathrm{s}$ for all emulsions, with a maximum deviation from the mean value of $7 \%$. As the viscosity of the oil was $28 \mathrm{mPa} \cdot \mathrm{s}$, the viscosity ratio was 0.9 , which is in the optimal area for droplet breakup in shear flow [12].

\subsection{Atomization of Emulsions}

Atomization experiments were performed in an atomization rig using a commercial pressure swirl atomizer of the type SKHN-MFP SprayDry ${ }^{\circledR}$ (core size 16, orifice diameter $0.34 \mathrm{~mm}$, Spraying Systems Deutschland GmbH, Hamburg, Germany). These type of nozzles are widely used in the spray drying of food emulsions [30]. The atomization rig is depicted schematically in Figure 1. A more detailed description of the setup is provided elsewhere [6]. The atomization rig was equipped with a 
high-pressure three-piston pump (Rannie LAB Typ 8.5, SPX FLOW Inc., Charlotte, NC, USA) to supply the emulsions through the atomizer at a pressure of 100 bar and a corresponding flow rate of $28.8 \mathrm{~L} / \mathrm{h}$. The emulsions were tempered to $20{ }^{\circ} \mathrm{C}$ and were gently stirred during the experiments to avoid creaming of the oil droplets. A sample of the spray was taken during atomization with a beaker, $25 \mathrm{~cm}$ below the nozzle orifice. The oil droplet size was measured offline with laser diffraction spectroscopy (HORIBA LA950, Retsch Technology GmbH, Haan, Germany). All atomization experiments were performed in triplicate.

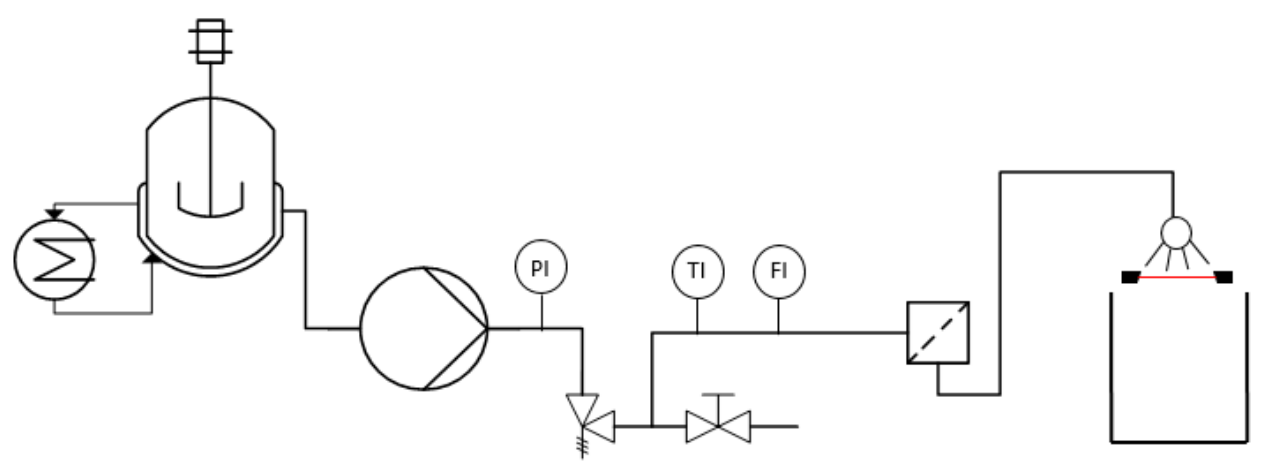

Figure 1. Scheme of the experimental setup for the atomization experiments [6]. The setup includes a tempered jacketed vessel; a high-pressure pump with a safety valve and an additional outlet valve; pressure, temperature, and volume flow sensors; a metal filter to avoid blockage of the nozzle orifice; a pressure swirl atomizer; a laser diffraction spectroscope for inline measurement of the spray droplet size; and a container to collect the emulsions after atomization.

To ensure that all emulsions were subjected to the same stresses during atomization, the spray droplet sizes were measured inline using a laser diffraction spectroscope (Spraytec, Malvern Instruments $\mathrm{GmbH}$, Herrenberg, Germany) as described in previous studies [7]. The laser was placed $25 \mathrm{~cm}$ underneath the nozzle exit, perpendicular to the nozzle axis center line. Spray droplet sizes were measured for $30 \mathrm{~s}$ and the diffraction pattern was processed according to the Fraunhofer theory to obtain time-averaged spray droplet size distributions (SDSDs). No significant difference in the SDSD of emulsions with different oil contents or with different emulsifier systems was observed (Appendix A), indicating that all emulsions were subjected to the same stresses during atomization.

\subsection{Single Droplet Experiments}

\subsubsection{Interfacial Tension Measurements}

Interfacial tensions $\sigma$ were measured with the pendant drop technique (OCA $15 \mathrm{LJ}$, DataPhysics Instruments $\mathrm{GmbH}$, Filderstadt, Germany) at constant temperature of $20^{\circ} \mathrm{C}$ for at least $100 \mathrm{~min}$. An oil droplet with a volume of $20 \mu \mathrm{L}$ containing the corresponding LMWE was created at the tip of a capillary in a solution of WPI and water. The concentrations of LMWEs in oil were set to $0.001 \mathrm{wt} . \%$, while the concentration of WPI in water was $0.5 \mathrm{wt} . \%$. These relatively low concentrations allow resolution of the interfacial effects, as also stated by Cheng et al. [31] and Neumann et al. [32] for comparable systems. Increasing the concentration resulted in very fast reduction of the interfacial tension and in some cases to detachment of the oil droplet from the capillary. The interfacial tension was calculated using the device-specific software based on droplet contour. As reference, measurements without protein or without LMWEs, as well as measurements between pure oil and water were also performed. All measurements were carried out at least in duplicate.

\subsubsection{Measurement of Coalescence Time}

The Diffusion and Coalescence Time Analyzer (DCTA), developed by Neumann et al. [33], can be used to determine the stability of emulsion droplets against coalescence. In this work, the setup 
was adapted to investigate the coalescence of oil droplets. The general idea of the measurement setup is the observation of single droplets, to determine their stability against coalescence. The setup is shown in Figure 2. The measurements were conducted in an optical glass cuvette (Hellma Analytica, Müllheim, Germany) in which $20 \mathrm{~mL}$ water phase were overlaid with $20 \mathrm{~mL}$ of oil phase. An oil droplet was formed by a Hamilton syringe with a repeating dispenser (Hamilton Company, Reno, NV, USA), which allowed to set the droplet size constantly to $2 \mu \mathrm{L}$. A variation of the coalescence time due to the droplet size was thereby minimized [34,35]. Shortly after the droplet was produced, the interfacial tension decreased due to emulsifier adsorption and the droplet detached from the tip of a bent needle $\left(d_{i}=0.58 \mathrm{~mm}, d_{a}=0.91 \mathrm{~mm}\right)$. The droplet floated to the interface and settled at the highest point of the slightly curved interface. The measurement of the coalescence time $t_{c}$ began with optical contact and ended with the complete disappearance of the droplet. Every $5 \mathrm{~s}$ a picture was taken by a single lens reflex camera (Canon 700d) with a macro objective (Canon EF 100 MM 1:2.8 USM). Droplets that did not disappear in a time span of $30 \mathrm{~min}$ were declared as stable.
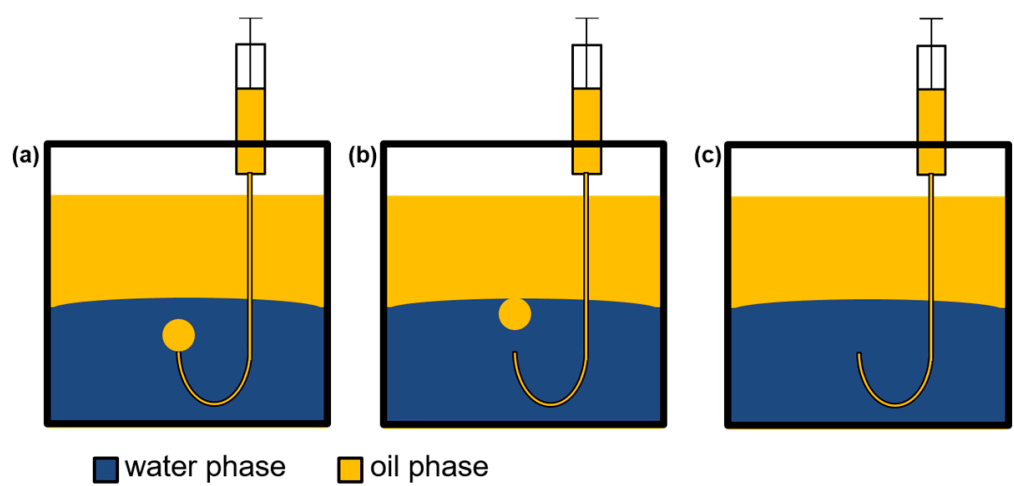

Figure 2. Different steps in the Diffusion and Coalescence Time Analyzer (DCTA) measurement setup. (a) Droplet is produced at the tip of the capillary. (b) Droplet floats to the interface and rests at the highest point. (c) Droplet disappears due to coalescence.

The water and oil phases had the same compositions as the oil and water phases in the atomized emulsions with $30 \mathrm{wt} . \%$ oil content (as in Section 2.2). Each experiment was repeated with nine consecutive droplets in two separate measurement cuvettes, resulting in 18 independent measurements for each emulsifier system.

\section{Results}

\subsection{Atomization of Emulsions}

To assess the influence of the LMWEs on the oil droplet breakup, excluding the effects of coalescence, emulsions with $1 \mathrm{wt} . \%$ oil content were atomized. The resulting number of cumulative distributions $Q_{0}$ of oil droplet size for the atomized emulsions with different emulsifiers are depicted in Figure 3a. This type of distribution was chosen as it allows to recognize the presence of small and large droplets to the same extent. The ODSDs of the feed emulsions are also depicted in Figure 3a. It can be seen that in all cases the ODSDs of the atomized emulsions are shifted towards smaller sizes compared to their respective feed emulsion. This indicates a strong oil droplet breakup upon atomization with all emulsifier systems. A breakup of the oil droplets upon atomization with pressure swirl nozzles was expected, as already reported in previous studies [6]. 


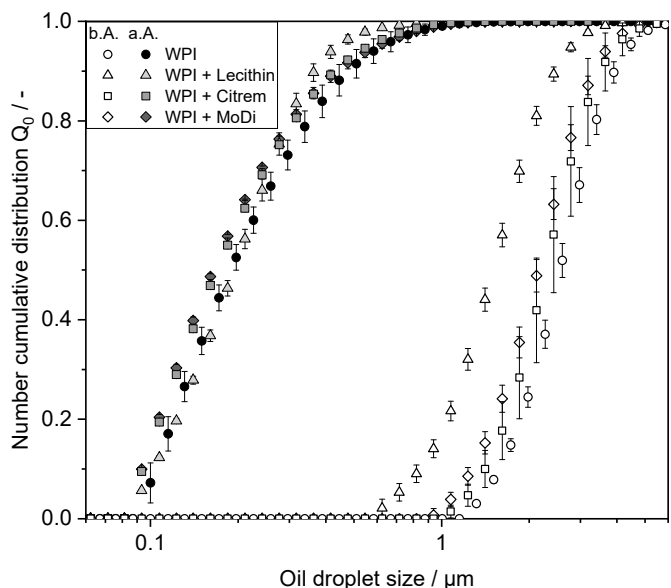

(a)

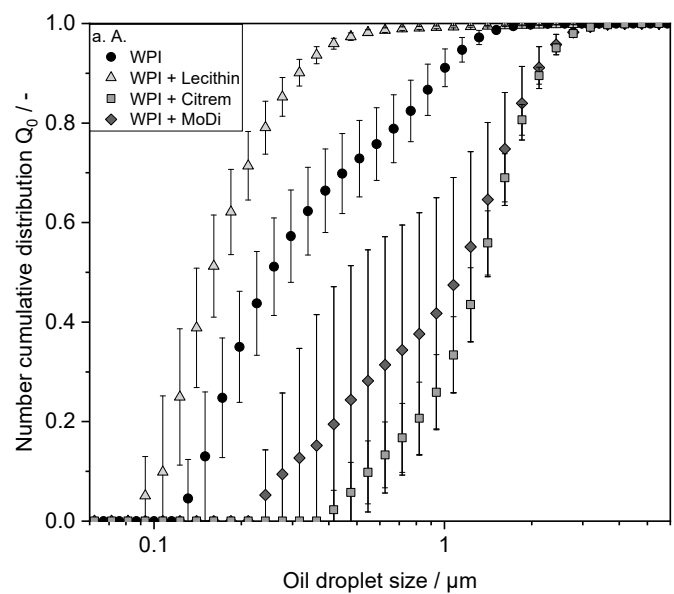

(b)

Figure 3. Number of cumulative distributions of oil droplet size of emulsions stabilized with (WPI) and WPI/LMWE (b. A.) and after (a. A.) atomization. (a) Oil content: 1 wt.\%; (b) Oil content: 30 wt.\%.

Only little differences in the ODSDs of the atomized emulsions stabilized with WPI and the different WPI/LMWE systems can be observed. In the case of the emulsion stabilized with WPI + lecithin, there is a slightly larger number of small droplets (between $0.3 \mu \mathrm{m}$ and $0.7 \mu \mathrm{m}$ ) compared to the other emulsifier systems, indicating a change in oil droplet breakup. This can be further appreciated by considering the $x_{90}$ diameters of the distributions, which are summarized in Figure 4. In the case of WPI + lecithin, the $x_{90}$ is significantly smaller $(p<0.05)$ than the $x_{90}$ of the atomized emulsions with the other emulsifier systems. Smaller initial oil droplet sizes were already evident for feed emulsions stabilized with WPI + lecithin, compared to the other emulsifier systems. However, this difference becomes relatively small after atomization. Studies in the literature have also reported that the addition of lecithin to protein stabilized emulsions resulted in smaller droplet sizes after homogenization processes [16]. No significant difference $(p<0.05)$ was observed in the values of $x_{90}$ after atomization of emulsions stabilized with WPI + citrem and WPI + MoDi, compared to emulsions stabilized with sole WPI. This indicates that, at least in the studied conditions, the addition of these LMWE do not favor nor hinder oil droplet breakup during atomization.

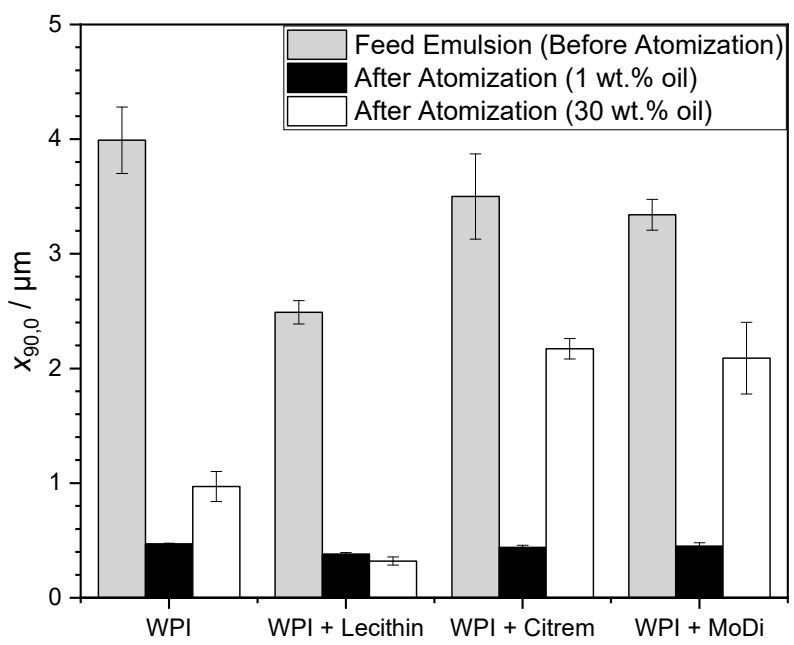

Figure 4. Summary of the mean $x_{90}$ diameters of oil droplet size of feed and atomized emulsions with different emulsifier systems and oil contents. Error bars correspond to standard deviations of three independent atomization experiments. 
To study the influence of the LMWEs on the coalescence of the oil droplets during atomization, experiments with emulsions with a disperse phase content of $30 \mathrm{wt} . \%$ were performed. The resulting number of cumulative distributions are depicted in Figure 3b. In contrast to the results of oil droplet breakup (Figure 3a), clear differences in the resulting ODSDs are observed between different emulsifier systems. The ODSD of the emulsion stabilized solely with WPI presents a bimodality, with a proportion of small droplets in the same range as the corresponding atomized emulsion with $1 \mathrm{wt} . \%$ oil (sizes between $0.1 \mu \mathrm{m}$ and $0.3 \mu \mathrm{m}$ ), followed by a proportion of larger droplets with sizes up to $1.5 \mu \mathrm{m}$. From Figure 4 it can be seen that the value of $x_{90}$ is almost doubled when increasing the oil content from $1 \mathrm{wt} . \%$ to $30 \mathrm{wt} . \%$. The presence of small droplets and the bimodality of the distribution support the hypothesis that oil droplet coalescence took place after oil droplet breakup. Oil droplet coalescence during the atomization of emulsions with effervescent atomizers has been reported in previous studies for similar emulsions following a similar approach [10].

The emulsions stabilized with WPI + citrem and WPI + MoDi also present a bimodality (Figure 3b). In this case, however, there is almost no proportion of droplets with sizes below $0.2 \mu \mathrm{m}$ and the size of the larger droplets range up to about $3 \mu \mathrm{m}$. The value of $x_{90}$ was in both cases almost five times higher than the corresponding value after atomization of emulsions with $1 \mathrm{wt.} \%$ (Figure 4). These results imply that coalescence of the oil droplets was promoted by the addition of citrem and MoDi in the oil phase, as compared to emulsions stabilized solely with WPI. This is in accordance with several studies in the literature, where an increased coalescence of oil droplets in emulsions was observed when combining dairy proteins with monoglycerides and fatty acid esters $[3,21,24]$. The results imply that the addition of citrem and MoDi hindered the stabilization of the newly created interface after oil droplet breakup by the protein in the system, leading to bigger oil droplets after atomization at high oil concentrations.

A very different behavior was seen for emulsions stabilized with WPI + lecithin. In this case, the emulsion presented a monomodal ODSD and the oil droplets were in the same range as the corresponding atomized emulsion with $1 \mathrm{wt} . \%$ oil. In fact, a slightly smaller value of $x_{90}$ was obtained for emulsions with $30 \mathrm{wt} . \%$ oil than with $1 \mathrm{wt} . \%$ (Figure 4), which can be considered within the experimental error. Evidently, the emulsifier system WPI + lecithin was capable of stabilizing the newly created interface after droplet breakup faster than the protein system alone. This is in agreement with some studies in the literature, which demonstrate synergetic interactions of lecithin with whey protein $[25,26]$. The results indicate that by addition of lecithin very small oil droplets can be obtained after atomization compared to the other studied WPI/LMWE systems, even at high oil contents.

\subsection{Interfacial Tension as Influenced by LMWE}

The interfacial tension between the water and the oil phases was determined as a function of the added LMWE. The time-dependent values of interfacial tension are depicted in Figure 5a-c. The interfacial tension between pure water and oil (water/oil) was constant over time at a value of $24.3 \mathrm{mN} / \mathrm{m}$ (solid black line). The interfacial tension between pure oil and the aqueous protein solution (water + WPI/oil) decreased so fast that the first measurable value after 0.1 min was already significantly lower than the pure water/oil system $(14 \mathrm{mN} / \mathrm{m})$. This was expected, as the protein concentration (0.5 wt.\%) was above the critical interfacial concentration (CIC). The value decreased to $11.4 \mathrm{mN} / \mathrm{m}$ after $100 \mathrm{~min}$ (solid grey line).

Figure 5a depicts the interfacial tension between an oil phase with added lecithin against a pure water phase (black dotted line) and against a water phase with added WPI (grey dotted line). The initial values of interfacial tension were lower than the corresponding values of the system without lecithin, and a reduction of the interfacial tension over time was observed. The interfacial tension of the system water + WPI/oil + lecithin reached a relative low value of $6.4 \mathrm{mN} / \mathrm{m}$ after $100 \mathrm{~min}$. This indicates that the combination of WPI and lecithin lowered the interfacial tension to a larger extent than the individual emulsifiers at the same concentrations. These results agree with studies in the literature, whereby synergetic effects at the interface between lecithin and WPI resulted in lower 
interfacial tensions [16]. The lower value of interfacial tension indicates an increased hydrophobicity by combination of these emulsifiers. The faster reduction of the interfacial tension with the system with lecithin can be explained by the fact that LMWEs present higher mobility and faster diffusion to the interface, compared to large protein molecules $[14,18]$.

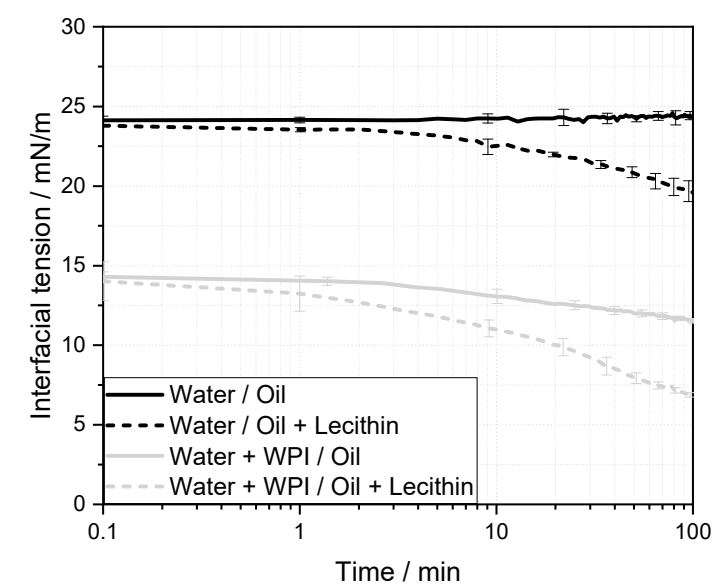

(a)

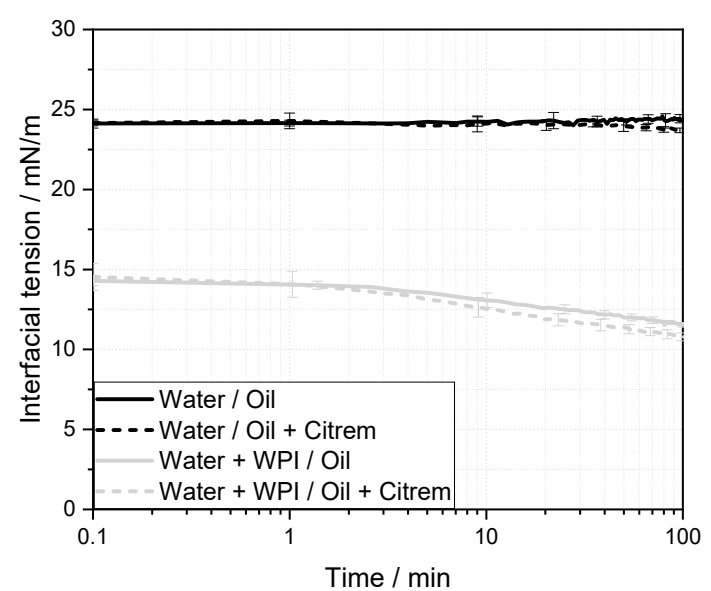

(b)

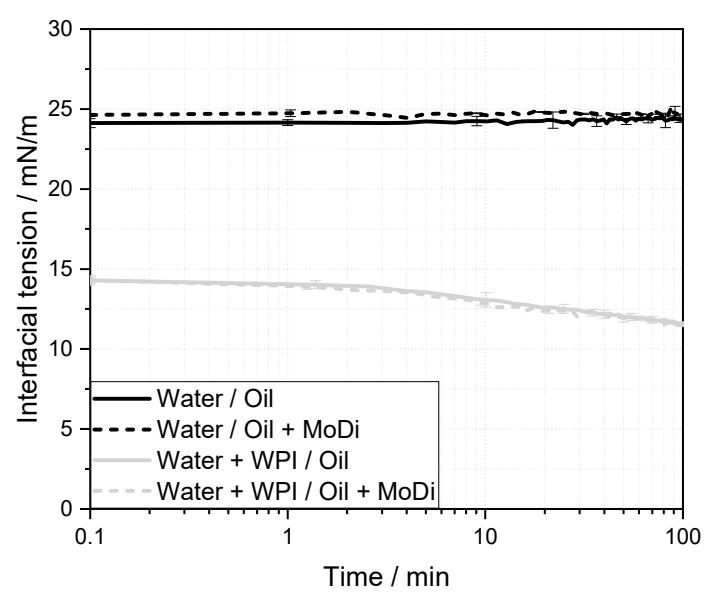

(c)

Figure 5. Measurements of interfacial tension over time between oil and water phases with different emulsifiers measured with the pendant drop method for $100 \mathrm{~min}$. (a) Oil phase with added lecithin. (b) Oil phase with added citrem. (c) Oil phase with added mono and diglycerides (MoDi).

Figure $5 \mathrm{~b}$ depicts the interfacial tension between an oil phase with added citrem against a pure water phase (black dotted line) and against a water phase with added WPI (grey dotted line). In this case, the initial values of interfacial tension were the same as the corresponding values of the system without citrem, and only a very slight reduction of the interfacial tension over time was observed. However, this reduction is almost negligible when compared to the effect of the addition of lecithin. In this case, the reduction of the interfacial tension is probably mainly caused by the protein at the interface.

Figure $5 \mathrm{c}$ depicts the interfacial tension between an oil phase with added MoDi against a pure water phase (black dotted line) and against a water phase with added WPI (grey dotted line). It can be seen that the curves behave similarly to the measurements without any added LMWEs. After $100 \mathrm{~min}$, the systems with added MoDi presented virtually the same interfacial tension values as the systems with pure oil. These results indicate that the addition of MoDi to the oil phase in the studied concentration 
is neither advantageous nor detrimental in the reduction of the interfacial tension. At the studied conditions the protein alone is responsible for the reduction of the interfacial tension in the system.

The emulsions for atomization experiments were prepared the day before atomization and stored overnight (Section 2.2). As interfacial tensions for the protein and LMWE containing systems did not reach equilibrium values even after $100 \mathrm{~min}$, interfacial tension measurements were repeated and measured overnight (data not shown). The trends shown in Figure 5 did not change.

\subsection{Coalescence Times as Influenced by LMWE}

Figure 6 presents the results obtained from the coalescence time analysis. Each point represents the coalescence time of a single droplet. Single measurement values scatter, especially for long coalescence times, as described by various authors [29,36-38]. In general, coalescence of droplets occur due to oscillations in the interfacial film. As the exact mechanisms of the interfacial film instability are still not understood in detail [39], stochastic methods are used for their description [40] and trends are discussed using individual data points [29]. In Figure 6 the red line indicates a coalescence time of $30 \mathrm{~min}$, over which all droplets were declared stable.

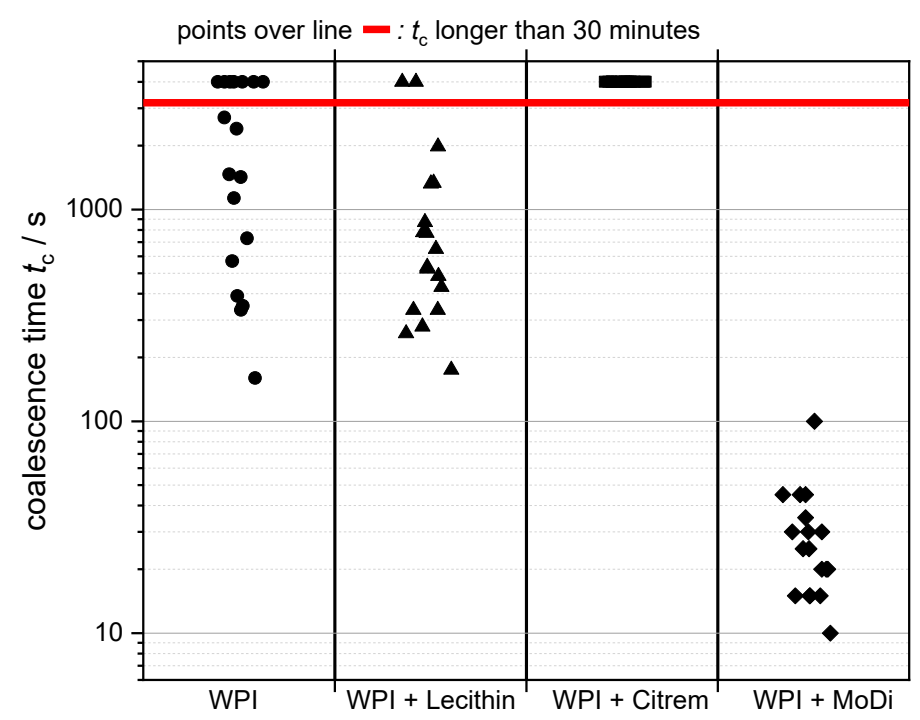

Figure 6. Coalescence time of single droplets with different emulsifier systems. Measurement points above the red line did not coalesce within $30 \mathrm{~min}$. Eighteen droplets were studied for each system.

The droplets stabilized with sole WPI and WPI + lecithin show a similar distribution of coalescence times. Both sole WPI and WPI + lecithin presented several stable droplets for over $30 \mathrm{~min}$ and a coalescence time of more than $100 \mathrm{~s}$ for the rest of the droplets. The droplets in the system with WPI + citrem were more stable than with sole WPI, as no droplets coalesced within the measurement time. The values of WPI + MoDi differ from the other systems. Most droplets were only stable for shorter than $2 \mathrm{~min}$, having a minimal coalescence time of $10 \mathrm{~s}$. No droplets were stable for over $30 \mathrm{~min}$. The observed differences are likely to be the result of a competitive adsorption of LMWE and WPI at the interface. Especially emulsifiers with low molecular weight are able to disturb the stabilization of interfaces by polymeric emulsifiers [41]. Specific studies on combinations of WPI with monoglycerides have demonstrated that these LMWEs can lead to a displacement of the protein and a destabilization of oil/water interfaces [22,42]. Differences in emulsifier hydrophobicity (HLB values) also resulted in a change of droplet stability in single droplet experiments in a study by Neumann et al. [43]. 


\section{Discussion}

The results from the atomization experiments indicate that breakup and coalescence of the dispersed oil droplets during atomization of oil-in-water emulsions are influenced by the addition of LMWEs. LMWEs are well-known to interact with proteins at oil/water interfaces [2,19]. Oil droplet breakup is generally known to depend on the interfacial tension between the oil and water phase, which is directly correlated to the emulsifier system. In this study, emulsions stabilized with WPI + lecithin presented a slightly increased oil droplet breakup, while no significant difference in the oil droplet breakup was observed with emulsions stabilized with sole WPI, WPI + citrem, and WPI + MoDi. These results can be explained by interfacial tension measurements (Figure 5). For the same mass concentration, the combination of WPI with lecithin presents the lowest value of interfacial tension after $100 \mathrm{~min}$. This indicates that synergetic effects of these two emulsifiers occur at the interface. A lower value of the interfacial tension facilitates the breaking up of droplets by increasing the capillary number (Equation (1)). In contrast, the addition of citrem or MoDi did not induce any substantial change in the interfacial tension as compared to WPI alone, at least in the examined time scale. This correlated well with the measured data for oil droplet breakup in atomization. Similar ODSDs were obtained for emulsions atomized at low oil content and stabilized with WPI, WPI + citrem, and WPI + MoDi.

On the contrary, different effects on the oil droplets' stabilization against coalescence were observed using the different LMWEs. From the literature it is known that protein emulsifiers require relatively long diffusion times and additionally need to change their configuration to absorb at the interface [2,18]. Therefore, coalescence of oil droplets after breakup is expected to take place in formulations with protein emulsifiers and highly dispersed phase contents [11]. This effect was observed in this study when increasing the oil content from $1 \mathrm{wt} . \%$ to $30 \mathrm{wt} . \%$ in emulsions stabilized with sole WPI. From the literature it is also known that the addition of LMWEs to protein stabilized systems can either improve or hinder the stabilization of oil droplets against coalescence by presenting cooperative or competitive behaviors at the interface [2]. In this study, stabilization of the droplets against coalescence was improved for emulsions stabilized with WPI + lecithin. This indicates a cooperative behavior of these emulsifiers at the interface. Synergetic effects of whey proteins with lipid-based lecithin, resulting in increased droplet stabilization, have also been reported in the literature $[25,26]$.

A higher degree of coalescence was observed for emulsions stabilized with WPI + citrem and WPI + MoDi in the atomization experiments. This effect can be explained by competitive interactions between the protein and these LMWEs. This can be due to the fact that the LMWEs adsorb at the interface at faster rates than the protein, and may displace the protein from the interface [22,42]. In the case of this study, the addition of citrem and MoDi in the studied concentrations probably disturbed the adsorption of the protein to the interface, delaying or even impeding the formation of the viscoelastic film around the oil droplets. By this, coalescence of the oil droplets may be promoted.

The differences in coalescence phenomena observed in the atomization experiments could only be predicted to a limited extent by the measurements in the DCTA. According to the results in Figure 6, similar coalescence times were observed for the systems WPI, WPI + lecithin, and WPI + citrem. However, clear differences in the coalescence of oil droplets were observed during the atomization experiments with these systems. Only in the case of WPI + MoDi was a higher degree of coalescence predicted, which was in accordance with the results from the atomization experiments. The different time scales between droplet interface generation and the collision of newly created droplets may explain the discrepancies of the results of the DCTA and the atomization experiments. In the DCTA experiments, a single droplet was formed with a relatively low surface area and several seconds passed from the droplet formation to the approximation of the droplet to the external oil/water interface. Due to the relatively high amount of emulsifier per surface area and the large time-scale, the emulsifier systems WPI, WPI + lecithin, and WPI + citrem had probably enough time to diffuse, arrange, and stabilize the droplet interface by the time the droplet came in proximity with the external oil/water interface. Therefore, long coalescence times were observed for these systems. In the case of the atomization experiments, a very large amount of surface was created very fast and coalescence 
after breakup took place in a lapse of milliseconds. The state of the interface in this time lapse is a determinant for the coalescence process. Unfortunately, this time frame cannot be reflected by the interfacial tension measurements. It is very likely that the effects leading to oil droplet coalescence during atomization are therefore too fast to be resolved with the available DCTA setup. The DCTA experiments showed, however, that LMWE and WPI interact at the interface, even when the interfacial tension does not change. Although no change in interfacial tension was observed between the systems with WPI and WPI + MoDi, significantly different coalescence times were obtained. The remaining challenge is to transfer these changes in interfacial properties to the coalescence probability of the emulsion in the times scales of the atomization process.

\section{Conclusions}

In this study, the influence of the addition of lipid-based LMWEs to whey protein stabilized oil-in-water emulsions on the oil droplet breakup and coalescence during atomization were investigated. Atomization experiments demonstrated that the combination of WPI with lecithin slightly promoted oil droplet breakup during atomization and led to a substantially better stabilization of the oil droplets against coalescence, compared to a system stabilized with sole WPI. This means that by addition of lecithin very small oil droplets can be obtained after atomization even at high oil contents. On the contrary, the addition of citrem and MoDi did not affect oil droplet breakup, but greatly promoted coalescence of the oil droplets. The results indicate synergetic interactions at the interface between WPI and lecithin and competitive interactions between WPI and citrem and WPI and MoDi.

Measurements of interfacial tensions and coalescence times of single droplets were performed and correlated to the atomization experiments. The results on oil droplet breakup were in good accordance with the observed differences in the interfacial tension measurements. In contrast, the results on oil droplet coalescence correlated only to a limited extent with the results of coalescence times of single droplet experiments. The discrepancies are likely due to the differences in the time scales of droplet breakup and coalescence during atomization and single droplet experiments. These results indicate that the use of the DCTA as a predictive tool for the coalescence process is limited to interfaces near equilibrium, like storage related coalescence processes. It could be therefore of interest to compare the storage stability of the spray-dried formulations to DCTA measurements. For a detailed discussion of the phenomena occurring at the interface, further studies on adsorption kinetics on a very short time scale are required.

The results of this study show that changes in the oil droplet size of emulsions take place during the atomization step of spray drying and they can be largely influenced by LMWE in the emulsion. This is of high relevance for spray dried, whey/dairy protein-based food products, in which the oil droplet size is an important quality parameter. The influence of LMWEs on the coalescence during the drying step of the spray drying and on the properties of the resulting powders are a matter of current investigation.

Author Contributions: Conceptualization, M.L.T.; methodology, M.L.T. and N.L.; validation, M.L.T., N.L., V.G. and H.P.K.; formal analysis, M.L.T.; investigation, M.L.T.; writing-original draft preparation, M.L.T. and N.L.; writing-review and editing, V.G. and H.P.K.; visualization, M.L.T. and N.L.; project administration, M.L.T. and V.G.; funding acquisition, V.G. and H.P.K. All authors have read and agreed to the published version of the manuscript.

Funding: This IGF project of the FEI was supported via AiF within the program for promoting the Industrial Collective Research (IGF) of the German Ministry of Economic Affairs and Energy (BMWi), based on a resolution of the German Parliament. Project 19312 N.

Acknowledgments: The authors express their gratitude to Pascal Hauns, Doll Chutani, Tammy Huberty, Luzie Geers, and Lydia Schütz for the experimental support.

Conflicts of Interest: The authors declare no conflict of interest. The funders had no role in the design of the study; in the collection, analyses, or interpretation of data; in the writing of the manuscript, or in the decision to publish the results. 


\section{Appendix A}

To ensure that all emulsions were subjected to the same stresses during atomization, irrespectively of the oil content and the emulsifier system, spray droplet sizes were measured inline during atomization with laser refraction spectroscopy. The resulting spray droplet size distributions for emulsions stabilized with WPI and with oil contents of $1 \mathrm{wt} . \%$ and $30 \mathrm{wt} . \%$ are depicted in Figure A1a. No differences in the spray droplet size distributions were observed. Similar results were obtained for the other emulsifier systems. The resulting spray droplet size distributions for emulsions with $30 \mathrm{wt} . \%$ oil stabilized with different emulsifier systems are depicted in Figure A1b. No differences in the spray droplet size distributions were observed.

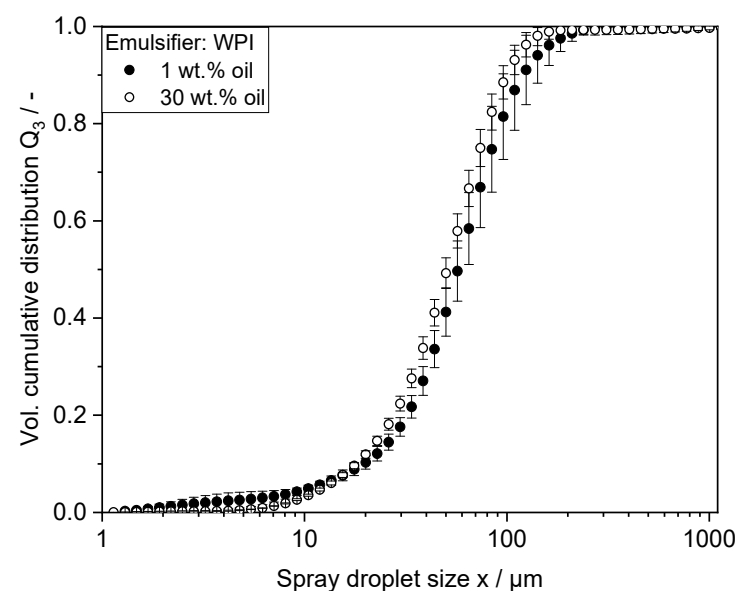

(a)

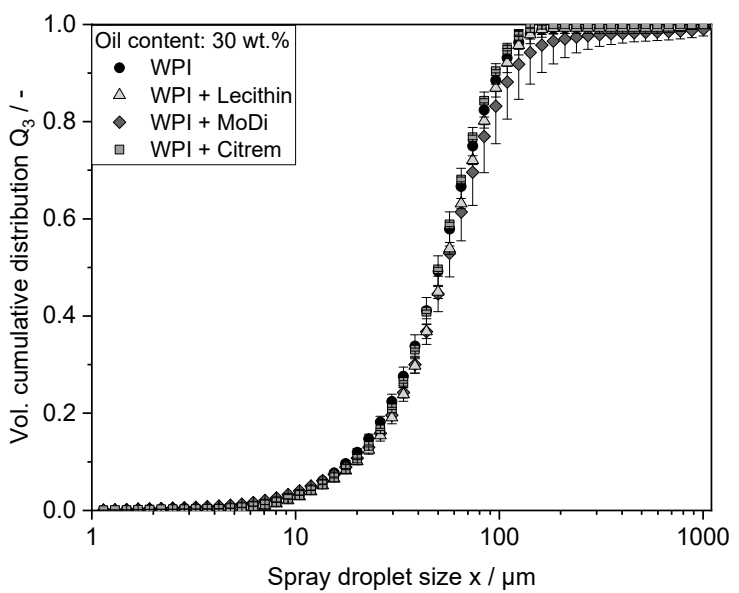

(b)

Figure A1. Spray droplet size distributions of: (a) emulsions stabilized with WPI with oil content of 1 wt. $\%$ and 30 wt.\%; (b) emulsions with 30 wt.\% oil content stabilized with WPI and WPI/LMWE.

\section{References}

1. Chen, J.; Dickinson, E. Effect of monoglycerides and diglycerol-esters on viscoelasticity of heat-set whey protein emulsion gels. Int. J. Food Sci. Technol. 1999, 34, 493-501. [CrossRef]

2. Bos, M.A.; van Vliet, T. Interfacial rheological properties of adsorbed protein layers and surfactants: A review. Adv. Colloid Interface Sci. 2001, 91, 437-471. [CrossRef]

3. Drapala, K.P.; Auty, M.A.E.; Mulvihill, D.M.; O'Mahony, J.A. Influence of emulsifier type on the spray-drying properties of model infant formula emulsions. Food Hydrocoll. 2017, 69, 56-66. [CrossRef]

4. Oosting, A.; van Vlies, N.; Kegler, D.; Schipper, L.; Abrahamse-Berkeveld, M.; Ringler, S.; Verkade, H.J.; van der Beek, E.M. Effect of dietary lipid structure in early postnatal life on mouse adipose tissue development and function in adulthood. Br. J. Nutr. 2014, 111, 215-226. [CrossRef]

5. McClements, D.J.; Li, Y. Structured emulsion-based delivery systems: Controlling the digestion and release of lipophilic food components. Adv. Colloid Interface Sci. 2010, 159, 213-228. [CrossRef]

6. Taboada, M.L.; Karbstein, H.P.; Gaukel, V. Spray drying of oil-in-water emulsions: Oil droplet breakup during the atomization by pressure-swirl atomizers. In Proceedings of the 29th European Conference on Liquid Atomization and Spray Systems, Paris, France, 2-4 September 2019.

7. Kleinhans, A.; Hornfischer, B.; Gaukel, V.; Schuchmann, H.P. Influence of viscosity ratio and initial oil drop size on the oil drop breakup during effervescent atomization. Chem. Eng. Process.-Process Intensif. 2016, 109, 149-157. [CrossRef]

8. Schröder, J.; Kleinhans, A.; Serfert, Y.; Drusch, S.; Schuchmann, H.P.; Gaukel, V. Viscosity ratio: A key factor for control of oil drop size distribution in effervescent atomization of oil-in-water emulsions. J. Food Eng. 2012, 111, 265-271. [CrossRef]

9. Munoz-Ibanez, M.; Azagoh, C.; Dubey, B.N.; Dumoulin, E.; Turchiuli, C. Changes in oil-in-water emulsion size distribution during the atomization step in spray-drying encapsulation. J. Food Eng. 2015, 167, 122-132. [CrossRef] 
10. Kleinhans, A.; Stähle, P.; Schröder, J.; Gaukel, V.; Schuchmann, H.P. Impact of oil content on effervescent atomization of oil-in-water emulsions. In Proceedings of the 25th European Conference on Liquid Atomization and Spray Systems, Chania, Greece, 1-4 September 2013.

11. Karbstein, H.P.; Schubert, H. Developments in the Continuous Mechanical Production of O/W-Macro-Emulsions. Chem. Eng. Process. 1995, 34, 205-211. [CrossRef]

12. Grace, H.P. Dispersion phenomena in high viscosity immiscible fluid systems and application of static mixers as dispersion devices in such systems. Chem. Eng. Commun. 1982, 14, 225-277. [CrossRef]

13. Armbruster, H. Untersuchungen zum Kontinuierlichen Emulgierprozess in Kolloidmuehlen Unter Beruecksichtigung Spezifischer Emulgatoreigenschaften und der Stroemungsverhaeltnisse im Dispergierspalt. Ph.D. Thesis, University of Karlsruhe, Karlsruhe, Germany, 1990.

14. van Aken, G.A. Competitive adsorption of protein and surfactants in highly concentrated emulsions: Effect of coalescence mechanisms. Colloids Surf. A Physicochem. Eng. Asp. 2003, 213, 209-219. [CrossRef]

15. O'Brien, R.D. Fats and Oils: Formulating and Processing for Applications, 3rd ed.; CRC Press: Boca Raton, FL, USA, 2009.

16. Drapala, K.P.; Auty, M.A.E.; Mulvihill, D.M.; O'Mahony, J.A. Influence of lecithin on the processing stability of model whey protein hydrolysate-based infant formula emulsions. Int. J. Dairy Technol. 2015, 68, 322-333. [CrossRef]

17. Chesters, A.K. The modelling of coalescence processes in fluid-liquid dispersions: A review of current understanding. Chem. Eng. Res. Des. 1991, 69, 259-270.

18. Lam, R.S.H.; Nickerson, M.T. Food proteins: A review on their emulsifying properties using a structure-function approach. Food Chem. 2013, 141, 975-984. [CrossRef]

19. Nylander, T.; Arnebrant, T.; Bos, M.; Wilde, P. Chapter 5: Protein/Emulsifier Interactions. In Food Emulsifiers and Their Applications, 2nd ed.; Hasenhuettl, G.L., Hartel, R.W., Eds.; Springer: New York, NY, USA, 2008; pp. 89-171.

20. Dickinson, E.; Yamamoto, Y. Effect of lecithin on the viscoelastic properties of $\beta$-lactoglobulin-stabilized emulsion gels. Food Hydrocoll. 1996, 10, 301-307. [CrossRef]

21. Danviriyakul, S.; McClements, D.J.; Decker, E.; Nawar, W.W.; Chinachoti, P. Physical Stability of Spray-Dried Milk Fat Emulsion as Affected by Emulsifiers and Processing Conditions. J. Food Sci. 2002, 67, 2183-2189. [CrossRef]

22. Cejudo Fernández, M.; Carrera Sánchez, C.; Rodríguez Niño, M.R.; Rodríguez Patino, J.M. Structural characteristics of adsorbed protein and monoglyceride mixed monolayers at the air-water interface. Food Hydrocoll. 2007, 21, 906-919. [CrossRef]

23. Chen, J.; Dickinson, E. Viscoelastic Properties of Protein-Stabilized Emulsions: Effect of Protein-Surfactant Interactions. J. Agric. Food Chem. 1998, 46, 91-97. [CrossRef]

24. Matsumiya, K.; Takahashi, Y.; Nakanishi, K.; Dotsu, N.; Matsumura, Y. Diglycerol esters of fatty acids promote severe coalescence between protein-stabilized oil droplets by emulsifier-protein competitive interactions. Food Hydrocoll. 2014, 42, 397-402. [CrossRef]

25. Wang, S.; Shi, Y.; Tu, Z.; Zhang, L.; Wang, H.; Tian, M.; Zhang, N. Influence of soy lecithin concentration on the physical properties of whey protein isolate-stabilized emulsion and microcapsule formation. J. Food Eng. 2017, 207, 73-80. [CrossRef]

26. Bylaite, E.; Nylander, T.; Venskutonis, R.; Jönsson, B. Emulsification of caraway essential oil in water by lecithin and $\beta$-lactoglobulin: Emulsion stability and properties of the formed oil-aqueous interface. Colloids Surf. B Biointerfaces 2001, 20, 327-340. [CrossRef]

27. Won, J.Y.; Krägel, J.; Makievski, A.V.; Javadi, A.; Gochev, G.; Loglio, G.; Pandolfini, P.; Leser, M.E.; Gehin-Delval, C.; Miller, R. Drop and bubble micro manipulator (DBMM) -A unique tool for mimicking processes in foams and emulsions. Colloids Surf. A Physicochem. Eng. Asp. 2014, 441, 807-814. [CrossRef]

28. Dickinson, E.; Murray, B.S.; Stainsby, G. Coalescence stability of emulsion-sized droplets at a planar oil-water interface and the relationship to protein film surface rheology. J. Chem. Soc. Faraday Trans. 1 1988, 84, 871-883. [CrossRef]

29. Neumann, S.M.; van der Schaaf, U.S.; Karbstein, H.P. Investigations on the relationship between interfacial and single droplet experiments to describe instability mechanisms in double emulsions. Colloids Surf. A Physicochem. Eng. Asp. 2018, 553, 464-471. [CrossRef] 
30. Barbosa-Cánovas, G.V.; Ortega-Rivas, E.; Juliano, P.; Yan, H. Food Powders: Physical Properties, Processing, and Functionality, 1st ed.; Food Engineering Series; Springer: New York, NY, USA, 2005.

31. Cheng, J.; Cui, J.; Ma, Y.; Yan, T.; Wang, L.; Li, H.; Li, X. Effects of soy-to-milk protein ratio and sucrose fatty acid ester addition on the stability of ice cream emulsions. Food Hydrocoll. 2016, 60, 425-436. [CrossRef]

32. Neumann, S.M.; Scherbej, I.; van der Schaaf Ulrike, S.; Karbstein, H.P. Investigations on the influence of osmotic active substances on the structure of water in oil emulsions for the application as inner phase in double emulsions. Colloids Surf. A Physicochem. Eng. Asp. 2018, 538, 56-62. [CrossRef]

33. Neumann, S.M.; van der Schaaf, U.S.; Schuchmann, H.P. The Diffusion and Coalescence Time Analyzer (DCTA): A novel experimental setup for investigating instability phenomena in double emulsions. Food Struct. 2017, 12, 103-112. [CrossRef]

34. Politova, N.I.; Tcholakova, S.; Tsibranska, S.; Denkov, N.D.; Muelheims, K. Coalescence stability of water-in-oil drops: Effects of drop size and surfactant concentration. Colloids Surf. A Physicochem. Eng. Asp. 2017, 531, 32-39. [CrossRef]

35. Basheva, E.S.; Gurkov, T.D.; Ivanov, I.B.; Bantchev, G.B.; Campbell, B.; Borwankar, R.P. Size Dependence of the Stability of Emulsion Drops Pressed against a Large Interface. Langmuir 1999, 15, 6764-6769. [CrossRef]

36. Lee, J.C.; Hodgson, T.D. Film flow and coalescence-I Basic relations, film shape and criteria for interface mobility. Chem. Eng. Sci. 1968, 23, 1375-1397. [CrossRef]

37. Ban, T.; Kawaizumi, F.; Nii, S.; Takahashi, K. Study of drop coalescence behavior for liquid-liquid extraction operation. Chem. Eng. Sci. 2000, 55, 5385-5391. [CrossRef]

38. Kumar, M.K.; Ghosh, P. Coalescence of Air Bubbles in Aqueous Solutions of Ionic Surfactants in Presence of Inorganic Salt. Chem. Eng. Res. Des. 2006, 84, 703-710. [CrossRef]

39. Kamp, J.; Villwock, J.; Kraume, M. Drop coalescence in technical liquid/liquid applications: A review on experimental techniques and modeling approaches. Rev. Chem. Eng. 2017, 33, 1-47. [CrossRef]

40. Gillespie, T.; Rideal, E.K. The coalescence of drops at an oil-water interface. Trans. Faraday Soc. 1956, 52, $173-183$. [CrossRef]

41. Pays, K.; Giermanska-Kahn, J.; Pouligny, B.; Bibette, J.; Leal-Calderon, F. Coalescence in Surfactant-Stabilized Double Emulsions. Langmuir 2001, 17, 7758-7769. [CrossRef]

42. McSweeney, S.L.; Healy, R.; Mulvihill, D.M. Effect of lecithin and monoglycerides on the heat stability of a model infant formula emulsion. Food Hydrocoll. 2008, 22, 888-898. [CrossRef]

43. Neumann, S.M.; Wittstock, N.; van der Schaaf, U.S.; Karbstein, H.P. Interactions in water in oil in water double emulsions: Systematical investigations on the interfacial properties and emulsion structure of the outer oil in water emulsion. Colloids Surf. A Physicochem. Eng. Asp. 2018, 537, 524-531. [CrossRef] 